\title{
The Knowledge, Attitudes and Practices (KAP) Regarding Human Papilloma Virus (HPV) Among Women in Karachi, Pakistan
}

\author{
Humera Ismail ${ }^{1}$, Dur-e-shahwar ${ }^{1}$, Muhammad Noman Rashid ${ }^{2}$ \\ ${ }^{1}$ Department of Obstetrics and Gynaecology, Aga Khan University Hospital, Karachi, Pakistan \\ ${ }^{2}$ Department of Physiology, Shaheed Mohtarma Benazir Bhutto Medical College, Karachi, Pakistan
}

Email address:

drnomanrashid@outlook.com (M. N. Rashid)

\section{To cite this article:}

Humera Ismail, Dur-e-shahwar, Muhammad Noman Rashid. The Knowledge, Attitudes and Practices (KAP) Regarding Human Papilloma Virus (HPV) Among Women in Karachi, Pakistan. American Journal of Biomedical and Life Sciences. Vol. 5, No. 4, 2017, pp. 69-72. doi: 10.11648/j.ajbls.20170504.12

Received: April 15, 2017; Accepted: May 12, 2017; Published: July 18, 2017

\begin{abstract}
Background: The burden of STIs in Pakistan is much larger than reported. Various research studies indicate that the knowledge of sexually transmitted infections (STIs) and Human Papilloma Virus (HPV) in the women is low. The objective of this study is to assess the knowledge, attitudes and practice regarding STIs, HPV and sexual behaviors of contraceptive practice among women in Karachi, Pakistan. Methods: The current study was conducted in a tertiary care hospital in Karachi from Aug 2014- Aug 2015, including 600 women (aged 19-50 years) by convenience sampling technique from waiting areas of out-patient clinics. Results: The mean age of participants was $39.5 \pm 10.7$ years. Eighty eight percent women $(\mathrm{n}=529)$ were married, $8 \%(\mathrm{n}=50)$ female were unmarried and around $3 \%(\mathrm{n}=19)$ female were divorced, separated or widowed. Participants with no knowledge about STIs and viruses causing some cancers were $57 \%(\mathrm{n}=341)$ and $70 \%(\mathrm{n}=$ 418) respectively. There was no knowledge about Pap smear in $80 \%(\mathrm{n}=479)$ of study population and the proportion of women not attending the annual gynecological examination were $88 \%(\mathrm{n}=525)$. Vaccine acceptability was found to be as low as $38 \%(\mathrm{n}=225)$. A similar trend $12 \%(\mathrm{n}=71)$ was seen in the response about willing to pay by themselves for the vaccination cost. Conclusion: The current study highlights inadequate knowledge about STDS, HPV, cervical cancer and its screening among women. Public health awareness programs should be raised at community level in order to increase the health seeking behavior of women.
\end{abstract}

Keywords: Sexually Transmitted Infections, Human Papillomavirus (HPV), HPV Vaccine

\section{Introduction}

HPV infection is very common in women with early sexual activity (before the age of 25 years), usually this infection resolves without clinical consequence. [1] However it may persists in $10 \%$ of cases and progress to a higher grade and invasive cancer. Cervical intraepithelial neoplasia (CIN) can lead to invasive cancer in an immune competent woman within 10 to 20 years. [2] This slow progression helps in an effective secondary prevention based on screening using Papanicolaou (Pap smear or Pap test), visual inspection of the cervix with $3-5 \%$ acetic acid (VIA), HPV DNA testing, prophylactic HPV vaccination and treatment of precancerous lesions. [3]
Several factors contribute to high burden of disease include poor knowledge about the disease and screening test among general population. Moreover screening is not available in most parts of the country and routine pap- smear is not even done in gynecological practice. With the scarcity of epidemiological data, the only information about burden of disease is available through institutional and regional cancer registries, which may not be representative of true burden. [4], [5] Based on one such registry in urban setting cervical cancer was responsible for 3.6 percent of cancer mortality. [6] In another study, it was reported that only 5 percent of women in Pakistan were aware of screening and only 2.6 percent of women actually had Pap smear once a life. [7] 
Despite the active role of health care professionals in preventing and educating about cervical cancer few studies has been conducted which explores the current awareness about cervical cancer and HPV infection. In this study we aim to access the current knowledge amongst women about STIs, HPV, cervical cancer and its prevention. The findings from this study will be useful at the policy level to complement knowledge and awareness about this important public health issue.

\section{Methods}

A cross sectional study carried out in women attending the out-patient waiting area of a tertiary care hospital in Karachi from Aug 2014 - Aug 2015. Convenience sampling was applied. Women aged 19-50 years were included in the study. Illiterate women and those who refused to consent were excluded. After their written consent a self-administered questionnaire (available in English and Urdu) was used to assess the Knowledge, Attitude and Practices (KAP) regarding sexually transmitted infections, Human Papilloma Virus (HPV) among women in Karachi, Pakistan. Age groups were divided in four different categorizes. The questionnaire consisted of simple stated statements regarding knowledge attitude and practices. Data was entered and analyzed using SPSS version 21. Frequencies and percentages were calculated for categorical variables. Mean and standard deviation was calculated for continuous variables.

\section{Results}

Total 600 women were enrolled in this study. The mean age of participants was $39.5 \pm 10.7$ years. Eighty eight percent women $(n=529)$ were married, $8 \%(n=50)$ female were unmarried and around $3 \%(n=19)$ female were divorced, separated or widowed. Women with Primary education were $21 \%(\mathrm{n}=125)$, Middle and intermediate education was $52 \%(\mathrm{n}=309)$, and bachelor/master were $26 \%$ $(\mathrm{n}=153)$. Out of 600 women $97 \%(\mathrm{n}=583)$ were Muslim and $86 \%(\mathrm{n}=518)$ women were house wife. The sociodemographic characteristics of the study group are presented in Table 1 .

Table 1. Socio-demographic features of women Respondents. $(n=600)$.

\begin{tabular}{lll}
\hline Demographics & Parameters & $\mathbf{n}(\mathbf{\%})$ \\
\hline \multirow{2}{*}{ Age (years) } & Mean & 39.58 \\
& Std. Deviation & 10.78 \\
& Refused & $2(0.3)$ \\
& Single & $50(8.3)$ \\
Marital status & Married & $529(88.2)$ \\
& Divorced & $6(1.0)$ \\
& Separated & $4(0.7)$ \\
& Widow & $9(1.5)$ \\
& Primary & $125(20.8)$ \\
& Middle & $150(25)$ \\
& intermediate & $159(26.5)$ \\
& bachelor/master & $153(25.5)$ \\
& Doctor & $9(1.5)$ \\
& Nil & $4(0.7)$ \\
\hline
\end{tabular}

\begin{tabular}{lll}
\hline Demographics & Parameters & n (\%) \\
\hline \multirow{3}{*}{ Religion } & Muslim & $583(97.2)$ \\
& Christians & $7(1.2)$ \\
\multirow{2}{*}{ Working status } & Hindu & $10(1.7)$ \\
& House wife & $518(86.3)$ \\
& Working & $82(13.7)$ \\
\hline
\end{tabular}

This study showed $57 \%(\mathrm{n}=341)$ of participants had no knowledge about sexually transmitted diseases and 70\% $(\mathrm{n}=$ 418) had no knowledge that viruses may cause some cancers. Most women $83 \%(n=499)$ were unaware about HPV, HPV related lesions $89 \%(\mathrm{n}=533)$, its causal relation with cervical cancer $96 \%(\mathrm{n}=576)$ and that condom is protective against HPV 92\% $(\mathrm{n}=551)$. There was no knowledge about Pap smear in $80 \%(\mathrm{n}=479)$ of study population. Of the women who had knowledge of HPV, $48 \%(n=286)$ got the information from their doctor while $33 \%(n=197)$ gained this information from nurses and $20 \%(\mathrm{n}=117)$ from other resources. About $53 \%(\mathrm{n}=316)$ of the women did not know about routes of transmission of HPV. (Table 2)

Table 2. Knowledge about STI and HPV in women of Karachi. $(n=600)$.

\begin{tabular}{|c|c|c|}
\hline Knowledge & Response & n (\%) \\
\hline \multirow{2}{*}{$\begin{array}{l}\text { Knowledge about sexual transmitted } \\
\text { disease }\end{array}$} & Yes & $259(43.1)$ \\
\hline & No & $341(56.8)$ \\
\hline \multirow{2}{*}{$\begin{array}{l}\text { Knowledge that viruses may cause } \\
\text { some types of cancer }\end{array}$} & Yes & $182(30.3)$ \\
\hline & No & $418(69.6)$ \\
\hline \multirow{2}{*}{$\begin{array}{l}\text { Knowledge of the Human Papilloma } \\
\text { (HPV) Virus }\end{array}$} & Yes & $101(16.8)$ \\
\hline & No & $499(83.1)$ \\
\hline \multirow{2}{*}{$\begin{array}{l}\text { Knowledge about the HPV related } \\
\text { lesions }\end{array}$} & Yes & $67(11.1)$ \\
\hline & No & $533(88.8)$ \\
\hline \multirow{2}{*}{$\begin{array}{l}\text { Knowledge about the causal relation } \\
\text { between HPV and cervical cancer }\end{array}$} & Yes & $24(4.0)$ \\
\hline & No & $576(96.0)$ \\
\hline \multirow{2}{*}{$\begin{array}{l}\text { Knowledge that the condom protective } \\
\text { against HPV }\end{array}$} & Yes & $49(8.1)$ \\
\hline & No & $551(91.8)$ \\
\hline \multirow{2}{*}{ Knowledge about Pap smear } & Yes & $121(20.1)$ \\
\hline & No & $479(79.8)$ \\
\hline \multirow{3}{*}{ Source of knowledge about HPV } & Doctor & $286(47.6)$ \\
\hline & Nurse & $197(32.8)$ \\
\hline & Other & $117(19.5)$ \\
\hline \multirow{5}{*}{$\begin{array}{l}\text { Knowledge about routes of } \\
\text { transmission of HPV }\end{array}$} & Don't know & $316(52.6)$ \\
\hline & Sexual contact & $150(25.0)$ \\
\hline & Kissing & $19(3.1)$ \\
\hline & Handshaking & $69(11.5)$ \\
\hline & Other & $46(7.6)$ \\
\hline
\end{tabular}

Most of the women $60 \%(n=361)$ were not aware to use condoms during sexual intercourse. The proportion of women not attending the annual gynecological examination were higher $88 \%(\mathrm{n}=525)$. A similar trend was also seen in the response about ever having a pap smear. Table III shows the responses to sexual practices. (Table 3)

Vaccine acceptability was found to be as low as $38 \%(\mathrm{n}=$ 225). Similar response was received when inquired about consenting for their daughter's vaccination 37\% $(\mathrm{n}=220)$. However, most women responded negatively when asked about vaccine acceptability in their sons $88 \%(\mathrm{n}=529)$. A similar trend $12 \%(\mathrm{n}=71)$ was seen in the response about willing to pay by themselves for the vaccination cost. Table 4 
shows the responses to questions regarding HPV vaccine awareness.

Table 3. Attitude about STI and HPV of women Karachi. $(n=600)$.

\begin{tabular}{lll}
\hline Attitude & Response & n (\%) \\
\hline \multirow{2}{*}{ You or your partner use condom } & Yes & $239(39.8)$ \\
Regularly have an annual gynecological & Yes & $361(60.1)$ \\
examination & No & $75(12.5)$ \\
Ever had a pap smear & Yes & $525(87.5)$ \\
& No & $113(18.8)$ \\
Ever had an abnormal pap smear & Yes & $487(81.1)$ \\
& No & $594(1.0)$ \\
\hline
\end{tabular}

Table 4. Practices about HPV prevention and uses of HPV vaccination.

\begin{tabular}{lll}
\hline Practices & Response & n (\%) \\
\hline If the vaccine were to work at any age, & Yes & $225(37.5)$ \\
would you accept the HPV vaccine for & No & $375(62.5)$ \\
yourself? & & $220(36.7)$ \\
Would you consent for your daughter to & Yes & $380(63.3)$ \\
receive the vaccine? & No & $71(11.8)$ \\
Would you consent for your Son to & Yes & $529(88.2)$ \\
receive the vaccine? & No & $311(51.8)$ \\
& Government & $71(11.8)$ \\
Who should pay for the vaccine? & On self & $218(36.3)$ \\
\hline
\end{tabular}

\section{Discussion}

According to the findings of the current study the trends has been indicated regarding the knowledge, attitudes and practices regarding HPV among women. Lack of knowledge about cervical cancer and Pap smear and unfavorable attitude towards Pap smear test and prophylactic HPV vaccine can have negative impact on utilization of the test by women. On the other hand, cervical cancer preventive programs at community level can be effective in increasing cervical cancer knowledge, perceived susceptibility, and cancer prevention behavior. The purpose of this study was to evaluate the knowledge attitudes and practices (KAP) regarding HPV, cervical cancer and HPV vaccine. The result of this survey showed most respondents were not at all or very less aware of cervical cancer, HPV, and HPV vaccine.

Low levels of knowledge were also reported in one survey that showed only $19.0 \%$ of adult Korean women knew that HPV infection is a risk factor for cervical cancer. [8] In another study it was found that only $26.9 \%$ of Chinese women knew that HPV infection is risk factors for cervical cancer. [9] Similar low levels of knowledge regarding cervical cancer in the general population have also been seen in other Asian countries where there are no cervical cancer screening programs. [10] Several research studies have shown that health education through different teaching strategies is an effective way of imparting knowledge. Education is needed to prevent the incidence of cervical cancer. [11] By education, women can be empowered with knowledge of cervical cancer, its early warning symptoms and the availability of adequate therapies. [10] In the current study we found $43.2 \%$ of the participant had knowledge about sexually transmitted diseases. Only $16.8 \%$ participants had knowledge of HPV. Subjects further assessed about their knowledge about HPV itself then only $25 \%$ correctly reported sexual contact as the mode of transmission for HPV.

Other studies showed inadequate knowledge of the participants on the concerned topic and its prevention. [12], [13] It was observed that $61 \%$ of women practiced unprotected sexual intercourse and only 39\% women used condoms during intercourse. On the basis of these findings it can be expected that the knowledge regarding prevention of disease in general population is also less in our region.

Gynecologic examinations are important opportunities for cancer screening. This issue needs to be addressed to educate women and to make an informed choice in participating in cervical cancer screening. As studies undertaken in Turkey, Uganda, and other countries have demonstrated, there are frequently inadequate knowledge, inappropriate attitudes, and deficiencies in practices of cervical cancer prevention among health care providers. [14], [15] In a recent study in Pakistan, Imam SZ et al. reported that the knowledge of availability of screening for cervical cancer amongst general population was only $5 \%$ and only $2.6 \%$ had ever received a Pap test bone in their reproductive life. [7] In our study about only $9 \%$ women were attending gynecology clinics for their annual gynecological examination and only $13.7 \%$ of women had Pap smear done in their life.

Prevention of HPV infections is very essential in prevention of cervical cancer. The studies reported better knowledge in developed countries like the USA, Belgium and Australia, but other countries like Thailand, Turkey and China had poor information about HPV and HPV vaccine. [16] This vaccine has now available in Pakistan. As expected very few of the respondents were aware of the vaccine against HPV. A pleasing result found in the current study was most of the participants wanted to know more about the vaccine but HPV-vaccine acceptability for was only $37.5 \%$ and surprisingly most of the participants (88\% versus $63.3 \%)$ responded negatively when they asked about vaccine acceptability for their sons and daughters respectively. A similar trend was seen in the response about willing to pay for the vaccination cost by the government rather than by themselves.

\section{Conclusion}

This study highlights inadequate knowledge about STDS, HPV and cervical cancer and its screening among women. Public health awareness programs should be raised at community level to improve awareness of sexually transmitted diseases like HPV and importance of screening of cervical cancer and prophylactic HPV vaccination to reduce the incidence rate and mortality of cervical cancer is strongly recommended in order to increase the health seeking behavior of women. 


\section{References}

[1] Smith J S, Melendy A, Rana R K, Pimenta J M. Age-specific prevalence of infection with human papillomavirus in females: a global review. J Adolesc Health. 2008, 43 (4 Suppl): S5-S25.

[2] Schiffman M, Castle PE, Jeronimo J, Rodriguez AC, Wacholder S. Human papillomavirus and cervical cancer. Lancet. 2007, 370: 890-907.

[3] Luque A E, Hitti J, Mwachari C, Lane C, Messing S, Cohn SE, Adler D, Rose R, Coombs R. Prevalence of human papillomavirus genotypes in HIV-1-infected women in Seattle, USA and Nairobi, Kenya: results from the Women's HIV Interdisciplinary Network (WHIN). Int J Infect Dis. 2010, 14: 810-14.10.

[4] Aziz Z, Sana S, Saeed S, Akram M. Institution based tumor registry from Punjab: five year data based analysis. J Pak Med Assoc. 2003; 53: 350-353.

[5] Badar F, Anwar N, Meerza F, Sultan F. Cervical carcinoma in a Muslim community. Asian Pac J Cancer Prev. 2007 Jan-Mar; 8 (1): 24-6.

[6] Bhurgri Y, Nazir K, Shaheen Y, Usman A, Faridi N, et al. Patho-epidemiology of Cancer Cervix in Karachi South. Asian Pac J Cancer Prev. 2007; 8: 357- 62.

[7] Imam S Z, Rehman F, Zeeshan M M, Maqsood B, Asrar S, et al. Perceptions and practices of a pakistani population regarding cervical cancer screening. Asian Pac J Cancer Prev. 2008; 9: 42-44.

[8] Oh J K, Lim M K, Yun E H, Lee E H, Shin H R. Awareness of and attitude towards human papillomavirus infection and vaccination for cervical cancer prevention among adult males and females in Korea: a nationwide interview survey. Vaccine. 2010; 28 (7): $1854-60$.
[9] Xu C, Zhang W, Wu M, Zhang S. Knowledge of cervical cancer among 25-54-year-old women in Beijing. J Cancer Educ. 2011; 26 (3): 555-9.

[10] Mary B, D'Sa J L. Evaluation of an educational program on cervical cancer for rural women in Mangalore, Southern India. Asian Pac J Cancer Prev. 2014; 15 (16): 6603-8.

[11] Basu P, Hassan S, Fileeshia F, Mohamed S, Nahoodha A, Shiuna A, et al. Knowledge, attitude and practices of women in Maldives related to the risk factors, prevention and early detection of cervical cancer. Asian Pac J Cancer Prev. 2014; 15 (16): 6691-5.

[12] Vanslyke J G, Baum J, Plaza V, Otero M, Wheeler C, et al. HPV and cervical cancer testing and prevention: knowledge, beliefs, and attitudes among Hispanic women. Qual Health Res. 2008 May; 18: 584-596.

[13] Stark A, Gregoire L, Pilarski R, Zarbo A, Gaba A, et al. Human papillomavirus, cervical cancer and women's knowledge. Cancer Detect Prev. 2008; 32 (1): 15-22.

[14] Yaren A, Ozkilinc O G, Guler A, et al. Awareness of breast and cervical cancer risk factors and screening behaviours among nurses in rural region of Turkey. Eur J Cancer Care. 2008 May; 17 (3): 278-84.

[15] Mutyaba T, Mmiro F A, Weiderpass E. Knowledge, attitudes and practices on cervical cancer screening among the medical workers of Mulago Hospital, Uganda. BMC Medical Education. 2006; 6: 13. doi: 10.1186/1472-6920-6-13.

[16] Nganwai P, Truadpon P, Inpa C, Sangpetngam B, Mekjarasnapa M, et al. Knowledge, Attitudes and Practices vis-a-vis Cervical Cancer among Registered Nurses at the Faculty of Medicine, Khon Kaen University, Thailand. Asian Pac J Cancer Prev. 2008; 9: 15-18. 